\title{
Decomposition of wood, petiole and leaf litter by Xylaria species from northern Thailand
}

\author{
AUTHOR(S): \\ Osono, Takashi; To-Anun, Chaiwat; Hagiwara, \\ Yusuke; Hirose, Dai
}

\section{CITATION:}

Osono, Takashi ... [et al]. Decomposition of wood, petiole and leaf litter by Xylaria species from northern Thailand. Fungal Ecology 2011, 4(3): 210-218

\section{ISSUE DATE:}

2011-06

URL:

http://hdl.handle.net/2433/158360

\section{RIGHT:}

(c) 2010 Elsevier Ltd and The British Mycological Society.; This is not the published version. Please cite only the published version.; この論文は 出版社版でありません。引用の際には出版社版をご確認ご利用くださ い。 
1 Decomposition of wood, petiole, and leaf litter by Xylaria species from northern

2 Thailand

3

4 Takashi Osono*,1, Chaiwat To-Anun ${ }^{2}$, Yusuke Hagiwara ${ }^{3}$, Dai Hirose ${ }^{4}$

5

$6{ }^{1}$ Center for Ecological Research, Kyoto University, Otsu, Shiga 520-2113 Japan

$7 \quad 2$ Faculty of Agriculture, Chiang Mai University, Chiang Mai 50200 Thailand

$8{ }^{3}$ Graduate School of Agriculture, Kyoto University, Kyoto 606-8502 Japan

$9{ }^{4}$ College of Pharmacy, Nihon University, Funabashi, Chiba 274-8555 Japan

10

11 * Corresponding author. Tel.: +81 77549 8252; fax: +81 775498201.

12 E-mail address: tosono@ecology.kyoto-u.ac.jp

13 URL: http://www.ecology.kyoto-u.ac.jp/ tosono/

14

15 


\section{Abstract}

2

3 Ten Xylaria isolates (five obtained from wood and five from leaf litter) collected in

4 northern Thailand were tested for their ability to decompose 13 types of wood,

5 petiole, and lamina from seven tropical tree species under pure culture conditions.

6 The mass loss of the 13 substratum types caused by the 10 Xylaria isolates ranged

7 from $1.2 \%$ to $37.4 \%$ of the original mass. The substratum, the origin of isolates,

8 and the contents of lignin, total carbohydrates, and nitrogen in substrata affected

9 the mass loss. Mass loss was generally in the order: petiole > lamina $>$ wood.

10 Overall, the strains isolated from wood caused greater mass loss than the strains

11 isolated from litter. The mass loss caused by the 10 Xylaria isolates was

12 negatively affected by lignin and total carbohydrate contents and positively with

13 nitrogen content of the substrata. The values of mass loss in wood in the present

14 study were in the same range as those reported for other Xylaria isolates in

15 previous studies, whereas the mass loss in leaf litter were generally higher than

16 those of previous results, which is partly due to the relatively low lignin contents

17 in leaf litter used in the present study. 
1 Keywords: Decomposition, Litter, Tropical forest, Xylaria

2

3 Introduction

4

5 Fungi in the genus Xylaria (Xylariaceae, Xylariales, Sordariomycetes,

6 Ascomycota) are major components of mycobiota in tropical forests (Whalley 1993,

7 1996, 1997; Rogers 2000) and function as decomposers (e.g., Rogers et al. 1987,

8 1988; Gonzalez and Rogers 1989; Van der Gucht 1996; Osono 2007; Osono et al.

9 2008, 2009), endophytes (Rodrigues et al. 1993; Læssøe and Lodge 1994;

10 Rodrigues 1994; Bayman et al. 1998; Okane et al. 2008), pathogens (Ko and

11 Kunimoto 1991), and symbionts with termite nests (Rogers et al. 2005; Ju and

12 Hsieh 2007; Okane and Nakagiri 2007; Visser et al. 2009). Saprobic Xylaria

13 species inhabit the wood, petiole and lamina of tropical trees and take part in

14 decomposition and mineralization of these plant litters. Previous pure culture

15 studies have demonstrated that tropical wood-inhabiting Xylaria isolates are able

16 to cause significant mass loss in wood blocks of temperate beech and pine

17 (Pointing et al. 2003). Tropical endophytic Xylaria species have also been shown to 
1 produce extracellular enzymes to decompose plant substrates (Rodrigues et al.

2 1993; Pointing et al. 2003, 2005). However, few data have been available

3 regarding the ability of tropical Xylaria species to cause mass loss in wood and

4 leaf litter of tropical trees. Such studies are crucial for the understanding of

5 functional roles of Xylaria species in decomposition processes in tropical forests.

7 Xylaria isolates (five obtained from wood and five from leaf litter) to decompose

8 wood, petiole, and lamina of seven tropical tree species in pure culture tests and to

9 compare these results with the decomposing ability of other Xylaria isolates

10 reported in previous studies. The Xylaria isolates were collected in northern

11 Thailand and tested for their ability to cause loss of mass of 13 substratum types

12 (four woods, three petioles, and six laminas) during the laboratory incubation. We

13 hypothesized that wood and litter isolates would be able to decompose both wood,

14 petioles, and lamina regardless of the isolate origin and that petiole and lamina

15 would decompose faster than wood, which was attributable to chemical quality of the substrata. 


\section{$1 \quad$ Materials and methods}

2

3 Source of fungi and substrata for decomposition tests

4

5 Ten Xylaria isolates were used in the test, including five from wood and five from

6 leaf litter (Table 1). The 10 isolates were collected in October and November 2004

7 at three study sites in northern Thailand: Queen Sirikit Botanic Garden and Doi

8 Suthep National Park in Chiang Mai, and Naresuan University, Phayao Campus,

9 in Phayao. Isolates TP5BS72 and TP5BS101 were isolated from decomposing

10 Shorea obtusa leaves by means of the surface disinfection method (Osono et al.

11 2009). The other eight isolates were obtained from mass ascospores discharged

12 from fruiting bodies collected from twigs, branches, or logs, or petioles or primary

13 veins of tree leaves. Isolates were maintained on slants of $1 \%$ malt extract agar

14 medium [malt extract $1 \%$ and agar $2 \%(\mathrm{w} / \mathrm{v})]$ at $20^{\circ} \mathrm{C}$ in darkness until the tests

15 were performed.

Phylogenetic placement of the isolates was determined based on

17 morphological observations and on the DNA sequence of amplicons (566 to $596 \mathrm{bp}$ ) 
1 of rDNA ITS region obtained using primers ITS5 and ITS4 (White et al. 1990),

2 basically according to the method described in Hirose and Osono (2006). The

3 sequences of Xylaria isolates were compared with those of known species using

4 BLAST searching against the Genbank database (Table 1, Fig. 1). Two isolates

$5 \quad$ (TC041101 and TC041107) were identified as X. polymorpha and X. grammica

6 with reference to morphological observations of fruiting bodies from which the

7 isolates were obtained, whereas we were unable to identify the other six isolates

8 from fruiting bodies to species. In the present study, we referred to Xylaria

9 isolates obtained from fruiting bodies on woody substrata (twigs, branches, and

$10 \operatorname{logs}$ ) as wood isolates and those from leaf litter (laminae, petioles, and vein) as

11 litter isolates. The terms wood and litter isolates do not indicate that these

12 isolates are representatives of Xylaria species inhabiting or fruiting on wood and

13 litter. In fact, molecular phylogenetic analysis showed that TP041001 from twig

14 and TP5BS101 isolated from lamina can be regarded as being identical with

15 respect to their base sequences of ITS region (Table 1), suggesting that the

16 distinction between the wood and litter isolates is tentative. 
1 in the three study sites in February, October, and November 2004 and used as

2 substrata in the pure culture test (Table 2). Wood blocks (approx. $10 \times 10 \times 5 \mathrm{~mm}$ )

3 were cut out from living trees of Dipterocarpus tuberculatus, Tectona grandis,

4 Quercus kingiana, and Shorea obtusa. Newly shed leaves of Bauhinia variegata,

5 Macalanga denticulata, D. tuberculatus, T. grandis, S. obtusa, and Pinus kesiya

6 without obvious fungal or faunal attack were collected from the forest floor of the

7 three study sites. The leaves were separated into petiole and lamina for $B$.

8 variegata, $M$. denticulata, and $D$. tuberculatus. Lamina was cut into strips $1 \mathrm{~cm}$

9 wide (broadleaved trees) or pieces $2 \mathrm{~cm}$ in length (Pinus needles). The wood,

10 petiole, and lamina were oven-dried at $40^{\circ} \mathrm{C}$ for 1 week and preserved in vinyl

11 bags until the experiment was started. Trees are referred to as their genus names

12 in the present study for the sake of simplicity.

13

14 Decomposition tests

15

16 Samples of wood, petiole, and lamina were weighed and sterilized by exposure to

17 ethylene oxide gas at $60^{\circ} \mathrm{C}$ for 6 hours. The sterilized materials (approx. $400 \mathrm{mg}$ 
1 wood, approx. $400 \mathrm{mg}$ petiole, and $300 \mathrm{mg}$ lamina per dish) were placed on the

2 surface of Petri dishes (9 $\mathrm{cm}$ diameter) containing $20 \mathrm{ml}$ of $2 \%$ agar medium.

3 Inocula for each assessment were cut out of the margin of previously inoculated

4 Petri dishes on 1\% malt extract agar medium with a sterile cork borer $(6 \mathrm{~mm}$

5 diameter) and placed on the agar medium adjacent to materials, one plug per

6 plate. The plates were incubated for 12 weeks at $20^{\circ} \mathrm{C}$ in the dark. The plates were

7 sealed firmly with laboratory film during incubation so that moisture did not limit

8 decomposition on the agar medium. After incubation, the plant materials were

9 retrieved, oven-dried at $40^{\circ} \mathrm{C}$ for 1 week, and weighed. The initial, undecomposed

10 materials were also sterilized, oven-dried again at $40^{\circ} \mathrm{C}$ for 1 week, and weighed

11 to determine the original mass. Four plates were prepared for each isolate and

12 each substratum (wood, petiole, or lamina), and four uninoculated plates served

13 as a control for each substratum. Mass loss of wood, petiole, and lamina was

14 determined as a percentage of the original mass, taking the mass loss of materials

15 in the uninoculated and incubated control treatment into consideration, and the

16 mean values were calculated for each isolate and each substratum. Prior to the

17 tests, the sterilized substrata were placed on $1 \%$ malt extracted agar medium, and 
1 after 8 weeks of incubation at $20^{\circ} \mathrm{C}$ in darkness, no microbial colonies had

2 developed on the plates. Thus, the effectiveness of the sterilization method used in

3 the present study was assured.

4

$5 \quad$ Chemical analysis

6

7 The initial, undecomposed materials were combined to make one sample for each

8 substratum and ground in a laboratory mill (0.5 $\mathrm{mm}$ screen). The amount of lignin

9 in the samples was estimated by means of gravimetry, using hot sulfuric acid

10 digestion (King and Heath 1967). Samples were extracted with alcohol-benzene at

11 room temperature $\left(15-20^{\circ} \mathrm{C}\right)$, and the residue was treated with $72 \%$ sulfuric acid

12 (v/v) for $2 \mathrm{~h}$ at room temperature with occasional stirring. The mixture was

13 diluted with distilled water to make a $2.5 \%$ sulfuric acid solution and autoclaved

14 at $120^{\circ} \mathrm{C}$ for $60 \mathrm{~min}$. After cooling, the residue was filtered and washed with water

15 through a porous crucible (G4), dried at $105^{\circ} \mathrm{C}$, and weighed as acid-insoluble

16 residue. The filtrate (autoclaved sulfuric acid solution) was used for total

17 carbohydrate analysis. The amount of carbohydrate in the filtrate was estimated 
1 by means of the phenol-sulfuric acid method (Dubois et al. 1956). One $\mathrm{ml}$ of $5 \%$

2 phenol (v/v) and $5 \mathrm{ml}$ of $98 \%$ sulfuric acid (v/v) were added to the filtrate. The

3 optical density of the solution was measured using a spectrophotometer at $490 \mathrm{~nm}$,

4 using known concentrations of D-glucose as standards. Total N concentration was

5 measured using a combustion method with an automatic gas chromatograph (NC

6 analyzer SUMIGRAPH NC-900, Sumitomo Chemical, Osaka, Japan).

$8 \quad$ Statistical analysis

10 Pearson's correlation coefficients were calculated among initial chemical

11 properties. Factors affecting the mean values of mass loss of each substratum for

12 individual fungal isolates were analyzed with two-way ANOVA with substratum

13 (wood, petiole, lamina), isolate origin (wood, litter), and the interactions of

14 substratum $\times$ isolate origin as independent variables. We included this interaction

15 to test the substratum specificity of Xylaria isolates of wood and litter origin.

16 Regression analyses were performed for linear relationships between mass loss

17 values and initial chemical properties. Mass loss values were arcsin-transformed 
1 because the data were in the form of proportion. JMP version 6.0 for Macintosh

2 was used for the statistical analyses.

3

4 Results

5

$6 \quad$ Initial chemical composition

7

8 The 13 types of wood, petiole, and lamina examined in the pure culture tests

9 varied in their initial chemical composition (Table 2). The lignin content in wood

10 and lamina was generally greater than that in petiole. The total carbohydrate

11 content was greater in wood than in petiole and lamina. The content of extractives

12 was highest in lamina, followed by wood and then by petiole. Nitrogen content

13 was generally in the order: lamina $>$ petiole $>$ wood. When all substratum types

14 were included $(n=13)$, total carbohydrate content was significantly and negatively

15 correlated with the content of extractives $(\mathrm{R}=-0.629, \mathrm{P}<0.05)$ and nitrogen $(\mathrm{R}=-0.658, \mathrm{P}<0.05)$. 
1 Mass loss

2

3 The mass loss of the 13 types of wood, petiole, and lamina caused by the 10

4 Xylaria isolates tested in the pure culture tests ranged from $1.2 \%$ to $37.4 \%$ (Table

5 3). The mean greatest mass losses were observed for Bauhinia petiole and lamina

6 and Tectona lamina, whereas the mean lowest mass losses were observed for

$7 \quad$ Tectona wood and Dipterocarpus lamina (Table 3). The mean greatest mass loss of

8 wood, petiole, and lamina was caused by TP5BS101, followed by TP041004 and

9 TP041001 (Table 3).

11 Factors affecting mass loss

13 Substratum and isolate origin were significantly affected the mass loss

14 (substratum, $\mathrm{df}=2, \mathrm{~F}=14.81, \mathrm{P}<0.001$; isolate origin, $\mathrm{df}=1, \mathrm{~F}=5.62, \mathrm{P}=0.019$ ). Mass

15 loss tended to be in the order: wood < lamina < petiole, and wood isolates in

16 general caused greater mass loss than litter isolates (Fig. 2). The substratum $\times$

17 isolate origin interaction was not significant ( $\mathrm{df}=2, \mathrm{~F}=0.81, \mathrm{P}=0.84)$, suggesting 
1 that the substratum specificity was not significant for the $10 \mathrm{Xylaria}$ isolates. The

2 mass loss was significantly and negatively correlated with lignin content $(\mathrm{n}=130$,

$\left.3 \mathrm{R}^{2}=0.14, \mathrm{~F}=20.3, \mathrm{P}<0.0001\right)$ and total carbohydrate content $\left(\mathrm{n}=130, \mathrm{R}^{2}=0.06\right.$,

$4 \mathrm{~F}=8.7, \mathrm{P}=0.0038)$ and significantly and positively with nitrogen content $(\mathrm{n}=130$,

$\left.5 \quad \mathrm{R}^{2}=0.09, \mathrm{~F}=13.2, \mathrm{P}=0.004\right)$ (Fig. 2). Mass loss was not significantly correlated with

6 the content of extractives $\left(n=130, R^{2}=0.01, F=1.67, P=0.20\right)$.

7

8 Discussion

9

10 The present study showed that the 10 Xylaria isolates from northern Thailand

11 examined here were capable of causing mass loss of wood, petiole, and lamina of

12 tropical tree species, except that the litter isolate TC041105 was incapable of

13 causing significant mass loss of wood (Table 3). Both wood and litter isolates

14 decomposed wood, petiole, and lamina regardless of the original substrata (i.e.

15 wood or litter), as was demonstrated by the non-significant effect of the

16 substratum $\times$ isolate origin interaction. Such decomposition has been attributed

17 to the ability of Xylaria to produce cellulolytic and ligninolytic enzymes 
1 responsible for the hydrolysis, solubilization, and/or mineralization of organic

2 compounds (Whalley 1996; Rogers 2000; Pointing et al. 2003). Here, the results

3 are discussed with reference to previous results regarding wood and litter

4 decomposition by other Xylaria isolates in pure culture conditions (reviewed in

5 Table 4).

The mass loss values of wood reported in the present study are in the

7 same range as those reported to be caused by other Xylaria isolates from

8 temperate wood, despite the differences in experimental methods among the

9 previous studies (Table 4). In contrast, the mass loss values for tropical leaf litter

10 in the present study were generally higher than those caused by other Xylaria

11 isolates for other temperate and tropical leaf litter examined with the same

12 experimental methods (Table 4). In fact, the highest values in the present study

13 were recorded for leaf litter of Bauhinia, Tectona, and Macalanga, which had

14 relatively low lignin $(188-264 \mathrm{mg} / \mathrm{g})$ and high nitrogen contents $(9.2-14.2 \mathrm{mg} / \mathrm{g})$

15 (Table 2), whereas the lignin content of substrata used in the previous studies was

$16212-454 \mathrm{mg} / \mathrm{g}$, and the $\mathrm{N}$ content $6.0-11.5 \mathrm{mg} / \mathrm{g}$. Therefore, the relatively higher

17 values of mass loss in the present study were partly attributable to the difference 
1 in the chemical quality of the leaf litter.

2

The substrata (wood, petiole, lamina), the isolate origin, and chemical

3 composition of the substrata affected the mass loss (Fig. 2). The lower mass loss of

4 wood was primarily attributable to higher lignin and lower nitrogen contents

5 (Table 2). Lignin is one of the most recalcitrant components in wood and leaf litter

6 and often retards fungal growth and decomposition, and nitrogen is a major

7 essential element limiting fungal growth and enzyme production (Eriksson et al.

8 1990; Sinsabaugh et al. 2002; Waldrop and Zak 2006; Boberg et al. 2008).

9 Alternatively, factors potentially influencing the fungal decomposition of wood

10 and leaf components could include the anatomical structures of tissues and

11 secondary plant metabolites that inhibit or stimulate fungal growth, such as

12 essential oils and heartwood components (Lindeberg et al. 1980; Alfenas et al.

13 1982). Few studies other than the present one have compared the decomposition

14 of wood and leaf components by single Xylaria isolates (see Table 4).

15

The wood isolates tended to cause greater mass loss than the litter

16 isolates (Table 3), consistent with the finding of Osono and Takeda (2002) that

17 Xylaria isolates from woody cupules caused slightly greater mass loss than those 
1 from leaf litter. No other studies have made similar comparisons (Table 4),

2 making it difficult to draw general conclusions regarding the difference in

3 potential decomposing capabilities of wood- and litter-inhabiting Xylaria. It

4 should be noted that Xylaria sp. TP041001 (fruiting on a twig) was genetically

5 identical to TP5BS101 (which was isolated from leaf lamina collected in the same

6 study site as TP041001). This indicates that some species are able to colonize both

7 wood and leaf substrata, and makes the distinction between 'wood-' and

8 'litter-inhabiting Xylaria species' less clear. Further studies will be necessary to

9 compare decomposing and enzymatic activities of between Xylaria species

10 representative of wood and litter decomposers.

12 of tropical Xylaria species to decompose plant substrata. First, the 10 Xylaria

13 isolates caused lower mass loss values for Pinus needles than for broadleaved

14 lamina (Table 3), consistent with the patterns found in previous studies showing

15 that Xylaria isolates caused lower mass loss for coniferous wood or leaf litter than

16 for broadleaved litter (Table 4). This can be explained by the facts that coniferous

17 substrata generally have higher lignin content than broadleaves ones (e.g., 379 
$1 \mathrm{mg} / \mathrm{g}$ in Pinus kesiya needles vs $188-340 \mathrm{mg} / \mathrm{g}$ in broadleaved lamina, Table 2) and

2 that conifers contain primarily guaiacyl lignin, which is more resistant to fungal

3 decomposition than syringyl lignin in angiosperms (Eriksson et al. 1990).

4 Secondary, few studies but the present one have examined the decomposition of

5 tropical wood by Xylaria isolates (see Table 4). Xylaria species are well

6 represented in the tropics, and tropical Xylaria species are expected to be diverse

7 in terms of species richness, functioning, and interactions with plant hosts

8 (Whalley 1993, Rogers 2000). Future studies should expand the investigation to

9 more diverse Xylaria species of wood and litter origin and their abilities to

10 decompose tropical substrata, including coniferous tissues.

\section{Acknowledgments}

14 We thank Dr. M. Kakishima, Dr. S. Tokumasu, Dr. H. Takeda, Dr. S. Khamyong,

15 and Mr. T. Seramethakun for help with fieldwork in Thailand; Dr. A. Mori for help

16 with statistical analysis; Mr. O. Tateno for help with molecular analysis of Xylaria

17 isolates; and Dr. Elizabeth Nakajima for critical reading of the manuscript. This 
1 study was supported by Global COE Program A06 to Kyoto University.

2

3 References

4

5 Alfenas AC, Hubbes M, Couto L, 1982. Effect of phenolic compounds from Eucalyptus on the mycelial growth and conidial germination of Cryphonectria cubensis. Canadian Journal of Botany 60: 2535-2541.

8 Bayman P, Angulo-Sandoval P, Báez-Ortiz Z, Lodge DJ, 1998. Distribution and dispersal of Xylaria endophytes in two tree species in Puerto Rico. Mycological Research 102: 944-948.

11 Boberg J, Finlay RD, Stenlid J, Näsholm T, Lindahl BD, 2008. Glucose and ammonium additions affect needle decomposition and carbon allocation by the litter degrading fungus Mycena epipterygia. Soil Biology \& Biochemistry 40: 995-999.

15 Dubois M, Gilles KA, Hamilton JK, Rebers PA, Smith F, 1956. Colorimetric method for determination of sugars and related substances. Analytical Chemistry 28: 350-356. 
1 Eriksson KEL, Blanchette RA, Ander P, 1990. Microbial and enzymatic

2 degradation of wood and wood components. Springer, Berlin.

3 Fukasawa Y, Osono T, Takeda H, 2005. Decomposition of Japanese beech wood by diverse fungi isolated from a cool temperate deciduous forest. Mycoscience 46: $97-101$.

6 Gonzalez FSM, Rogers JD, 1989. A preliminary account of Xylaria of Mexico. Mycotaxon 34: 283-373.

8 Hirose D, Osono T, 2006. Development and seasonal variations of Lophodermium populations on Pinus thunbergii needle litter. Mycoscience 47: 242-247.

$10 \mathrm{Ju}$ YM, Hsieh HM, 2007. Xylaria species associated with nests of Odontotermes formosanus in Taiwan. Mycologia 99: 936-957.

King HGC, Heath GW, 1967. The chemical analysis of small samples of leaf material and the relationship between the disappearance and composition of leaves. Pedobiologia 7: 192-197.

15 Ko WH, Kunimoto RK, 1991. Quick decline of macadamia trees: association with Xylaria arbuscula. Plant Pathology 40: 643-644.

17 Koide K, Osono T, Takeda H, 2005. Fungal succession and decomposition of 
Camellia japonica leaf litter. Ecological Research 20: 599-609.

2 Læssøe T, Lodge DJ, 1994. Three host-specific Xylaria species. Mycologia 86: 436-446.

Lee JS, Ko KS, Jung HS, 2000. Phylogenetic analysis of Xylaria based on nuclear ribosomal ITS-5.8S-ITS2 sequences. FEMS Microbiology Letters 266: 10-19.

6 Lindeberg G, Lindeberg M, Lundgren L, Popoff T, Theander O, 1980. Stimulation of litter-decomposing basidiomycetes by flavonoids. Transactions of the British Mycological Society 75: 455-459.

9 Nilsson T, Daniel G, Kirk TK, Obst JR, 1989. Chemistry and microscopy of wood decay by some higher ascomycetes. Holzforschung 43: 11-18.

11 Okane I, Nakagiri A, 2007. Taxonomy of an anamorphic xylariaceous fungus from a termite nest found together with Xylaria angulosa. Mycoscience 48: 240-249. Nakagiri A, Potacharoen W, Suzuki K, 2008. Study of endophytic Xylariaceae in Thailand: diversity and taxonomy inferred from rDNA sequence analyses with saprobes forming fruit bodies in the field. 
2 Osono T, 2007. Ecology of ligninolytic fungi associated with leaf litter decomposition. Ecological Research 22: 955-974.

4 Osono T, Takeda H, 2002. Comparison of litter decomposing ability among diverse fungi in a cool temperate deciduous forest in Japan. Mycologia 94: 421-427.

6 Osono T, Fukasawa Y, Takeda H, 2003. Roles of diverse fungi in larch needle litter decomposition. Mycologia 95: 820-826.

8 Osono T, Hobara S, Koba K, Kameda K, 2006. Reduction of fungal growth and lignin decomposition in needle litter by avian excreta. Soil Biology \& Biochemistry 38: 1623-1630.

11 Osono T, Ishii Y, Hirose D, 2008. Fungal colonization and decomposition of Castanopsis sieboldii leaves in a subtropical forest. Ecological Research 23: 909-917. 
1 Pointing SB, Parungao MM, Hyde KD, 2003. Production of wood-decay enzymes,

2 north Sulawesi (Indonesia). Mycotaxon 29: 133-172.

Rogers JD, Callan BE, Rossman AY, Samuels GJ, 1988. Xylaria (Sphaerialese, Xylariaceae) from Cerro de la Neblina, Venezuela. Mycotaxon 31: 103-153. 

Mycologia 97: 914-923.

2 Sinsabaugh RL, Carreiro MM, Repert DA, 2002. Allocation of extracellular enzymatic activity in relation to litter composition, $\mathrm{N}$ deposition, and mass loss. Biogeochemistry 60: 1-24.

5 Van der Gucht K, 1996. Xylaria species from Papua New Guinea: cultural and anamorphic studies. Mycotaxon 60: 327-360.

7 Visser AA, Ros VID, de Beer ZW, Debets AJM, Hartog E, Kuyper TW, Læssøe T, Slippers B, Aanen DK, 2009. Levels of specificity of Xylaria species associated with fungus-growing termites: a phylogenetic approach. Molecular Ecology 18: 553-567.

11 Waldrop MP, Zak DR, 2006. Response of oxidative enzyme activities to nitrogen deposition affects soil concentrations of dissolved organic carbon. Ecosystems 9: 921-933.

14 Worrall JJ, Anagnost SE, Zabel RA, 1997. Comparison of wood decay among diverse lignicolous fungi. Mycologia 89: 199-219. 
3 Whalley AJS, 1996. The xylariaceous way of life. Mycological Research 100: 897-922.

5 Whalley AJS, 1997. Xylariaceae. In: Kevin H (Ed.), Biodiversity of Tropical

7 White TJ, Bruns T, Lee S, Taylor JW, 1990. Amplification and direct sequencing of

8 fungal ribosomal RNA genes for phylogenetics. In: Innis MA, Gelfand DH, Sninsky JJ, White TJ (Eds.), PCR Protocols: a Guide to Methods and Applications. Academic Press, New York, USA, pp. 315-322 
$1 \quad$ Figure legend

2

$3 \quad$ Fig 1 - Neighbour-joining tree based on the rDNA ITS sequences of the Xylaria

4 species used in the present study. Twenty sequences used in Lee et al. (2000) and

5 best identified BLAST match taxa were also included in the phylogenetic analysis.

6 Bootstrap values above 50\% are given adjacent to the corresponding node.

7

8 Fig 2 - Mean values of mass loss for wood, petiole, and lamina (upper, left) and

9 wood and litter isolates (upper, right) and relationship between the mean value of

10 mass loss for 10 Xylaria isolates and the initial contents of lignin (middle, left),

11 total carbohydrate (middle right), and nitrogen (lower, left). Open squares, wood;

12 open circles, petiole; open triangles, lamina.

13

14 


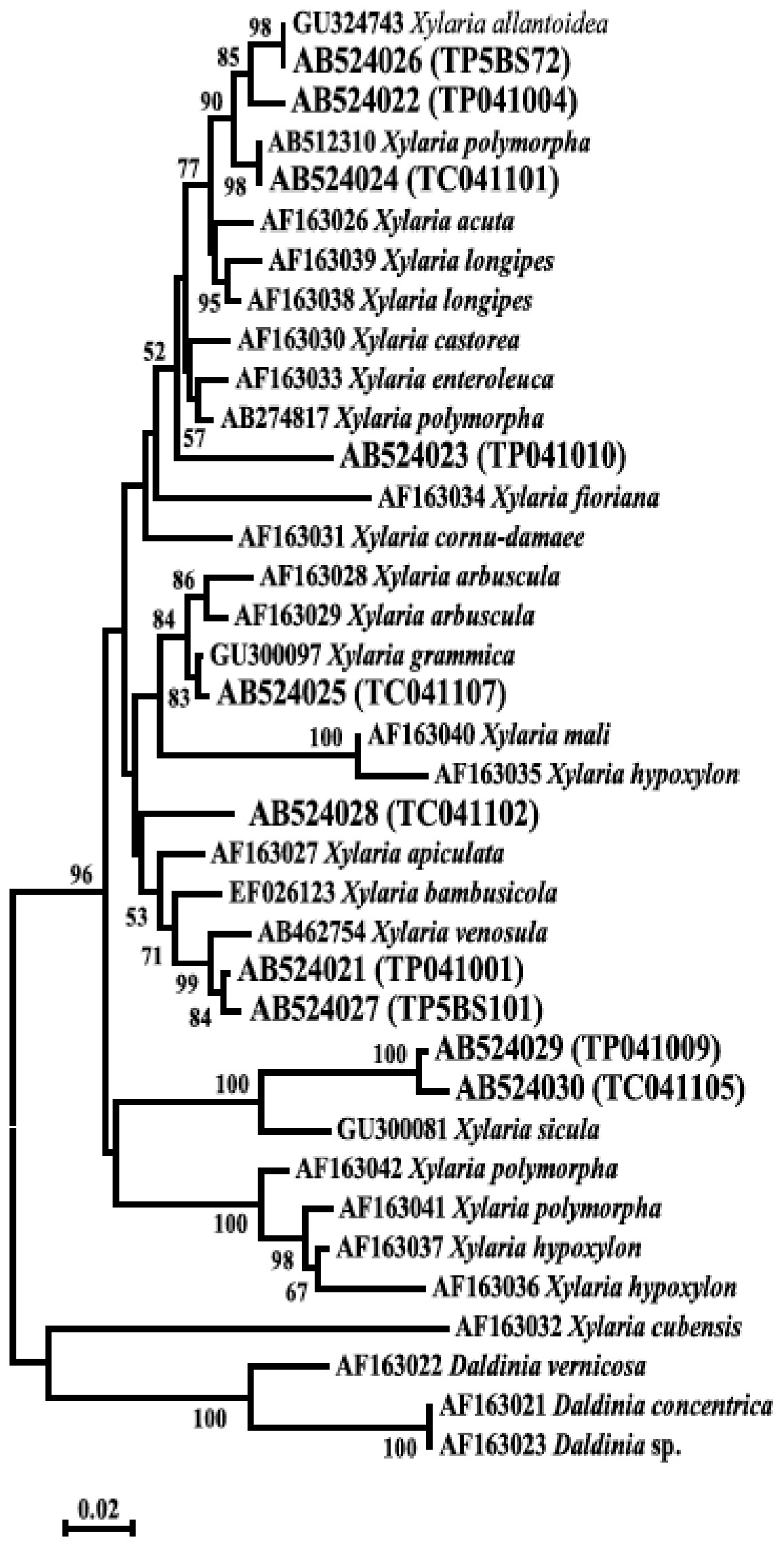


1 Osono et al. Fig 2
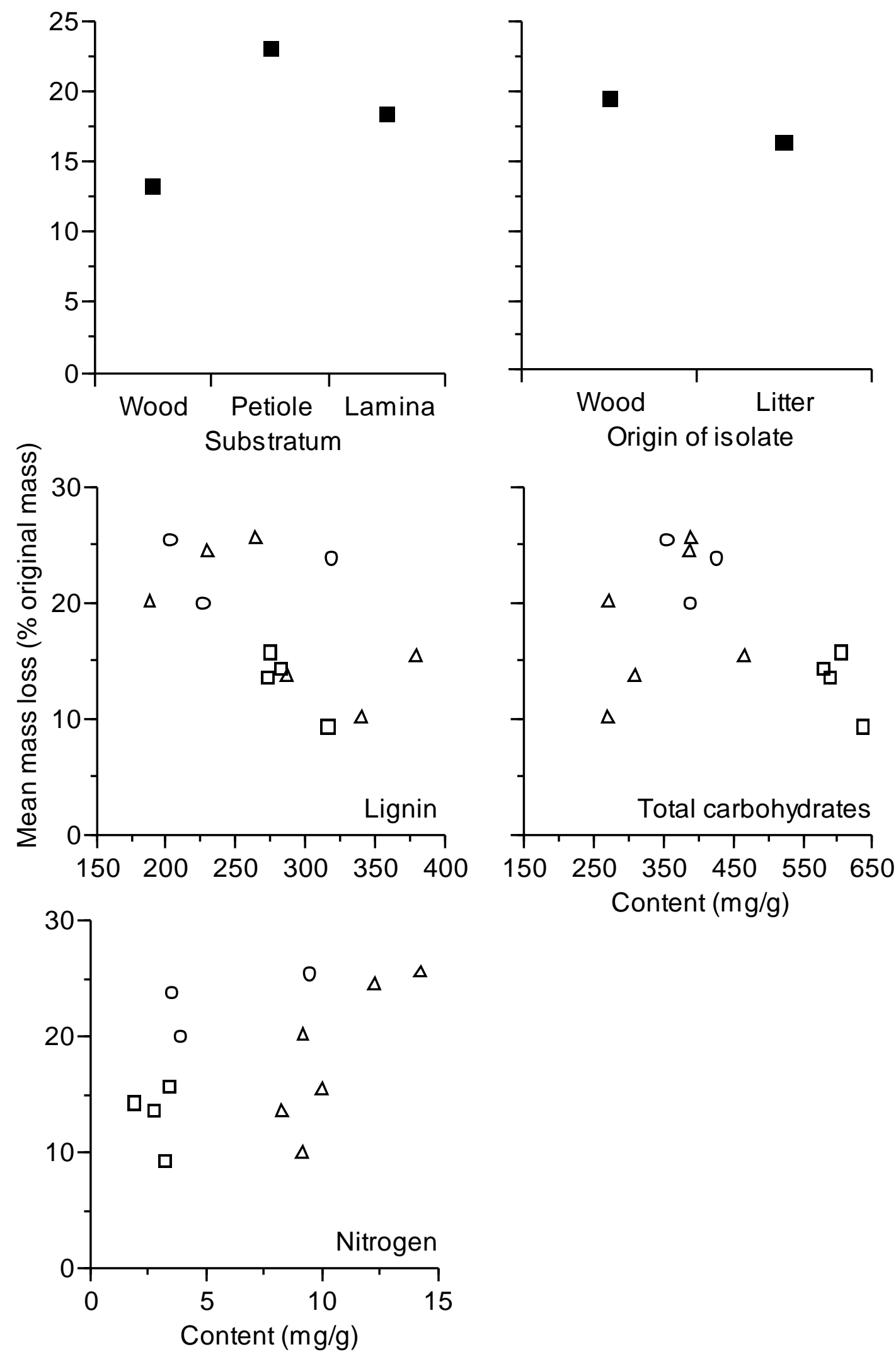
1 Osono et al. Table 1

4 Table 1 - Xylaria isolates used in the test.

\begin{tabular}{|c|c|c|c|c|c|c|c|}
\hline Strain code & $\begin{array}{l}\text { Collection } \\
\text { site }\end{array}$ & $\begin{array}{l}\text { Month of } \\
2004\end{array}$ & Substratum & $\begin{array}{l}\text { Method of } \\
\text { isolation }\end{array}$ & $\begin{array}{l}\text { DDBJ accession } \\
\text { number }\end{array}$ & $\begin{array}{l}\text { Best identified BLAST match taxa } \\
\text { (accession number) }\end{array}$ & $\begin{array}{l}\text { Sequence } \\
\text { similarity \% }\end{array}$ \\
\hline \multicolumn{8}{|c|}{ Wood isolates } \\
\hline ТР041001 & NU & Oct & Twig & MA & AB524021 & Xylaria venosula (AB462754) & 96 \\
\hline ТР041004 & NU & Oct & Branch & MA & AB524022 & Xylaria allantoidea (GU324743) & 97 \\
\hline ТР041010 & NU & Oct & Branch & MA & AB524023 & Xylaria polymorpha (AB274817) & 93 \\
\hline TC041101 & QSBG & Nov & $\log$ & MA & AB524024 & Xylaria polymorpha (AB512310) & 99 \\
\hline TC041107 & DS & Nov & $\log$ & MA & AB524025 & Xylaria grammica (GU300097) & 98 \\
\hline \multicolumn{8}{|c|}{ Litter isolates } \\
\hline TP5BS72 & NU & Oct & Lamina & $\mathrm{SD}$ & AB524026 & Xylaria allantoidea (GU324743) & 99 \\
\hline TP5BS101 & NU & Oct & Lamina & $\mathrm{SD}$ & AB524027 & Xylaria venosula (AB462754) & 96 \\
\hline TC041102 & QSBG & Nov & Petiole & MA & AB524028 & Xylaria bambusicola (EF026123) & 93 \\
\hline ТР041009 & NU & Oct & Petiole & MA & AB524029 & Xylaria sicula (GU300081) & 91 \\
\hline TC041105 & DS & Nov & Vein & MA & AB524030 & Xylaria sicula (GU300081) & 91 \\
\hline
\end{tabular}

5 NU Naresuan University, Phayao Campus, Phayao; QSBG Queen Sirikit Botanic Garden, Chiang Mai; DS Doi Suthep, 6 Chiang Mai.

7 MA mass ascospores from fruiting body, SD surface disinfection of lamina. 
1 Osono et al. Table 2

2

3

4 Table 2 - Contents ( $\mathrm{mg} / \mathrm{g}$ ) of organic chemical components and nitrogen, in wood, 5 petiole, and lamina of seven tropical tree species used in pure culture 6 decomposition tests.

\begin{tabular}{|c|c|c|c|c|}
\hline Type & Lignin & Total carbohydrate & Extractives & Nitrogen \\
\hline \multicolumn{5}{|l|}{ Wood } \\
\hline Shorea & 275 & 606 & 25 & 3.4 \\
\hline Quercus & 274 & 589 & 22 & 2.8 \\
\hline Dipterocarpus & 282 & 581 & 32 & 2.0 \\
\hline Tectona & 316 & 636 & 39 & 3.3 \\
\hline Mean & 287 & 603 & 29 & 2.9 \\
\hline \multicolumn{5}{|l|}{ Petiole } \\
\hline Bauhinia & 203 & 356 & 4 & 9.5 \\
\hline Macalanga & 227 & 389 & 12 & 3.9 \\
\hline Dipterocarpus & 318 & 426 & 39 & 3.5 \\
\hline Mean & 249 & 390 & 18 & 5.6 \\
\hline \multicolumn{5}{|l|}{ Lamina } \\
\hline Bauhinia & 229 & 387 & 45 & 12.2 \\
\hline Tectona & 264 & 390 & 63 & 14.2 \\
\hline Macalanga & 188 & 271 & 165 & 9.2 \\
\hline Pinus & 379 & 467 & 56 & 10.0 \\
\hline Shorea & 287 & 310 & 103 & 8.3 \\
\hline Dipterocarpus & 340 & 270 & 121 & 9.2 \\
\hline Mean & 281 & 349 & 92 & 10.5 \\
\hline
\end{tabular}


Osono et al. Table 3

3 Table 3 - Mass loss (\% original mass) of wood, petiole, and lamina decomposed at $20^{\circ} \mathrm{C}$ by 10 Xylaria isolates in vitro. Values

4 indicate mean \pm standard errors $(n=4)$.

\begin{tabular}{|c|c|c|c|c|c|c|c|c|c|c|}
\hline & \multicolumn{5}{|c|}{ Wood isolates } & \multicolumn{5}{|c|}{ Litter isolates } \\
\hline & ТР041001 & ТР041004 & ТР041010 & TC041101 & ТC041107 & TP5BS72 & TP5BS101 & TC041102 & ТР041009 & TC041105 \\
\hline \multicolumn{11}{|l|}{ Wood } \\
\hline Shorea & $18.1 \pm 1.7$ & $28.4 \pm 2.2$ & $21.8 \pm 0.7$ & $21.2 \pm 0.3$ & $8.8 \pm 0.3$ & $18.8 \pm 1.9$ & $20.7 \pm 3.1$ & $8.8 \pm 0.7$ & $7.8 \pm 0.8$ & $3.1 \pm 0.6$ \\
\hline Quercus & $19.6 \pm 5.4$ & $17.7 \pm 0.3$ & $13.3 \pm 1.9$ & $16.2 \pm 2.4$ & $9.0 \pm 1.3$ & $14.3 \pm 0.5$ & $18.4 \pm 0.7$ & $16.5 \pm 1.0$ & $9.8 \pm 0.4$ & $1.2 \pm 0.4$ \\
\hline Dipterocarpus & $18.3 \pm 1.1$ & $17.4 \pm 0.6$ & $13.7 \pm 0.5$ & $16.4 \pm 1.1$ & $10.2 \pm 0.3$ & $14.1 \pm 1.0$ & $25.9 \pm 0.9$ & $13.9 \pm 1.8$ & $8.6 \pm 0.4$ & $4.3 \pm 0.5$ \\
\hline Tectona & $11.8 \pm 3.3$ & $11.3 \pm 1.0$ & $12.2 \pm 0.7$ & $4.8 \pm 0.7$ & $8.5 \pm 0.3$ & $10.3 \pm 1.9$ & $19.4 \pm 1.3$ & $8.0 \pm 0.7$ & $4.5 \pm 0.4$ & $2.4 \pm 0.9$ \\
\hline \multicolumn{11}{|l|}{ Petiole } \\
\hline Bauhinia & $34.3 \pm 3.8$ & $32.6 \pm 2.9$ & $37.4 \pm 0.3$ & $20.9 \pm 1.0$ & $23.1 \pm 1.3$ & $22.4 \pm 1.8$ & $26.1 \pm 2.3$ & $23.8 \pm 2.1$ & $22.2 \pm 1.0$ & $11.3 \pm 1.4$ \\
\hline Macalanga & $23.0 \pm 2.4$ & $19.2 \pm 3.3$ & $31.5 \pm 2.1$ & $15.8 \pm 1.6$ & $12.9 \pm 0.9$ & $12.7 \pm 3.5$ & $24.0 \pm 3.4$ & $17.7 \pm 1.1$ & $26.9 \pm 2.9$ & $16.2 \pm 4.4$ \\
\hline Dipterocarpus & $30.7 \pm 1.6$ & $25.3 \pm 6.8$ & $28.2 \pm 3.5$ & $17.2 \pm 0.4$ & $13.8 \pm 1.1$ & $29.6 \pm 1.6$ & $28.7 \pm 3.6$ & $24.6 \pm 3.5$ & $23.3 \pm 3.8$ & $16.5 \pm 1.7$ \\
\hline \multicolumn{11}{|l|}{ Lamina } \\
\hline Bauhinia & $29.8 \pm 1.3$ & $28.1 \pm 1.8$ & $32.6 \pm 0.8$ & $28.1 \pm 0.6$ & $23.0 \pm 0.7$ & $23.6 \pm 2.5$ & $34.0 \pm 1.1$ & $24.9 \pm 1.5$ & $12.0 \pm 0.2$ & $10.3 \pm 1.0$ \\
\hline Tectona & $31.8 \pm 3.1$ & $24.0 \pm 2.9$ & $36.2 \pm 1.8$ & $22.4 \pm 1.9$ & $23.9 \pm 1.0$ & $29.6 \pm 1.9$ & $34.3 \pm 1.2$ & $27.7 \pm 2.1$ & $17.2 \pm 0.7$ & $10.5 \pm 0.2$ \\
\hline Macalanga & $23.2 \pm 3.8$ & $25.9 \pm 1.8$ & $12.4 \pm 2.1$ & $25.8 \pm 0.3$ & $25.5 \pm 2.1$ & $27.8 \pm 1.4$ & $26.8 \pm 1.4$ & $9.0 \pm 2.6$ & $15.4 \pm 1.1$ & $11.3 \pm 1.4$ \\
\hline Pinus & $15.7 \pm 2.3$ & $22.6 \pm 0.8$ & $15.0 \pm 1.3$ & $13.8 \pm 0.7$ & $16.0 \pm 0.7$ & $22.1 \pm 0.4$ & $25.8 \pm 1.4$ & $5.8 \pm 0.4$ & $10.4 \pm 0.9$ & $8.4 \pm 0.5$ \\
\hline Shorea & $16.7 \pm 3.0$ & $21.3 \pm 1.2$ & $10.4 \pm 2.4$ & $10.0 \pm 1.8$ & $14.0 \pm 1.9$ & $17.9 \pm 2.9$ & $23.7 \pm 3.4$ & $7.5 \pm 0.4$ & $9.8 \pm 2.5$ & $6.7 \pm 1.2$ \\
\hline Dipterocarpus & $12.7 \pm 2.0$ & $14.6 \pm 1.3$ & $6.9 \pm 2.0$ & $4.1 \pm 0.5$ & $11.8 \pm 1.7$ & $13.9 \pm 1.4$ & $20.0 \pm 1.3$ & $4.6 \pm 0.6$ & $7.8 \pm 0.5$ & $5.3 \pm 0.7$ \\
\hline
\end{tabular}


Osono et al. Table 4

Table 4 - A review of mass loss (\% original mass) of wood and litter of tropical and temperate trees caused by wood- and litter-isolates of Xylaria of tropical and temperate origins. Bold case indicates tropical isolates of Xylaria. Italicized numbers indicate the data of conifer decomposition. Numbers of isolates tested are in parentheses.

\begin{tabular}{|c|c|c|c|c|c|c|c|c|c|}
\hline \multirow[b]{2}{*}{ Substrata } & \multicolumn{2}{|c|}{ Wood decomposition } & \multicolumn{2}{|c|}{ Litter decomposition } & \multicolumn{4}{|l|}{ Method } & \multirow[t]{2}{*}{ Reference } \\
\hline & Wood isolates & Litter isolates & Wood isolates & Litter isolates & Medium & Sterilization & $\begin{array}{l}\text { Temperature } \\
\left({ }^{\circ} \mathrm{C}\right)\end{array}$ & $\begin{array}{l}\text { Period } \\
\text { (wk) }\end{array}$ & \\
\hline Fagus sylvatica & $2.6-10.3(12)$ & nd & nd & nd & S & $\mathrm{AC}$ & 25 & 12 & 1 \\
\hline Pinus sylvestris & $0.0-3.4(12)$ & nd & nd & nd & S & $\mathrm{AC}$ & 25 & 12 & \\
\hline Pinus sylvestris & $3.3-18.4(4)$ & nd & nd & nd & S & $\mathrm{AC}$ & 25 & 16 & \\
\hline Betula alleghaniensis & $5.9-6.6(2)$ & nd & nd & nd & S & $\mathrm{AC}$ & 25 & 12 & 3 \\
\hline Pinus taeda & $2.9-5.2(2)$ & nd & nd & nd & S & $\mathrm{AC}$ & 25 & 12 & \\
\hline Fagus crenata & $2.7-5.4(3)$ & nd & nd & nd & M & EG & 25 & 12 & 4 \\
\hline Fagus crenata & nd & nd & $4.0-14.4(2)^{*}$ & $5.5-9.9(8)$ & $\mathrm{W}$ & $\mathrm{AC}$ & 20 & 8 & 5 \\
\hline Chamaecyparis obtusa & nd & nd & nd & $3.0(1)$ & $\mathrm{W}$ & EG & 20 & 12 & 8 \\
\hline Tropical trees & & & & & & & & & \\
\hline
\end{tabular}




\begin{tabular}{|c|c|c|c|c|c|c|c|c|c|}
\hline Castanopsis sieboldii & nd & nd & $13.5(1)$ & $13.8(1)$ & $\mathrm{W}$ & EG & 20 & 12 & 9 \\
\hline Shorea obtusa & nd & nd & nd & $9.3-10.3(2)$ & $\mathrm{W}$ & EG & 20 & 12 & 10 \\
\hline \multicolumn{10}{|l|}{ Broadleaved, 4 to 5} \\
\hline Coniferous, 1 tree sp. & nd & nd & $13.8-22.6(5)$ & $5.8-25.8(5)$ & $\mathrm{W}$ & EG & 20 & 12 & \\
\hline
\end{tabular}

1 * Xylaria carpophila inhabiting cupules.

2 nd not determined.

3 Medium: S soil, M, malt extract agar, W water agar.

4 Sterilization of substrata: AC autoclaving, EG ethylene oxide gas.

5 Reference: 1 Pointing et al. (2003), 2 Nilsson et al. (1989), 3 Worrall et al. (1997), 4 Fukasawa et al. (2005), 5 Osono and Takeda 6 (2002), 6 Koide et al. (2005), 7 Osono et al. (2003), 8 Osono et al. (2006), 9 Osono et al. (2008), 10 Osono et al. (2009), 11 This 7 study. 